\title{
Measurements of photo-oxidation products from the reaction of a series of alkyl-benzenes with hydroxyl radicals during EXACT using comprehensive gas chromatography
}

\author{
J. F. Hamilton ${ }^{1}$, A. C. Lewis ${ }^{2}$, C. Bloss ${ }^{1}$, V. Wagner ${ }^{1}$, A. P. Henderson ${ }^{3}$, B. T. Golding ${ }^{3}$, K. Wirtz ${ }^{4}$, M. Martin-Reviejo ${ }^{4}$, \\ and M. J. Pilling ${ }^{1}$ \\ ${ }^{1}$ University of Leeds, Department of Chemistry, Woodhouse Lane, Leeds, LS2 9JT, UK \\ ${ }^{2}$ University of York, Department of Chemistry, Heslington, York, YO10 5DD, UK \\ ${ }^{3}$ School of Natural Sciences - Chemistry, Bedson Building, University of Newcastle upon Tyne, Newcastle upon Tyne NEI \\ 7RU, UK \\ ${ }^{4}$ Fundación Centro de Estudios Ambientales del Mediterráneo (CEAM), EUPHORE laboratories, C/Charles Darwin, 14-Parc \\ Technológico, Paterna, Valencia, Spain
}

Received: 7 May 2003 - Published in Atmos. Chem. Phys. Discuss.: 1 August 2003

Revised: 24 October 2003 - Accepted: 2 November 2003 - Published: 13 November 2003

\begin{abstract}
Photo-oxidation products from the reaction of a series of alkyl-benzenes, (benzene, toluene, $p$-xylene and 1,3,5-trimethyl-benzene) with hydroxyl radicals in the presence of $\mathrm{NO}_{\mathrm{x}}$ have been investigated using comprehensive gas chromatography $(\mathrm{GC} \times \mathrm{GC})$. A GC $\times \mathrm{GC}$ system has been developed which utilises valve modulation and independent separations as a function of both volatility and polarity. A number of carbonyl-type compounds were identified during a series of reactions carried out at the European Photoreactor (EUPHORE), a large volume outdoor reaction chamber in Valencia, Spain. Experiments were carried as part of the EXACT project (Effects of the oXidation of Aromatic Compounds in the Troposphere). Two litre chamber air samples were cryo-focused, with a sampling frequency of 30 minutes, allowing the evolution of species to be followed over oxidation periods of 3-6 hours. To facilitate product identification, several carbonyl compounds, which were possible products of the photo-oxidation, were synthesised and used as reference standards.

For toluene reactions, observed oxygenated intermediates found included the co-eluting pair $\alpha$-angelicalactone/4oxo-2-pentenal, maleic anhydride, citraconic anhydride, benzaldehyde and $p$-methyl benzoquinone. In the $p$-xylene experiment, the products identified were E/Z-hex-3-en-2,5dione and citraconic anhydride. For 1,3,5-TMB reactions, the products identified were 3,5-dimethylbenzaldehyde, 3,5dimethyl-3H-furan-2-one and 3-methyl-5-methylene-5Hfuran-2-one. Preliminary quantification was carried out on identified compounds using liquid standards. Comparison of FTIR and $\mathrm{GC} \times \mathrm{GC}$ for the measurement of the parent aro-
\end{abstract}

Correspondence to: J. F. Hamilton

(jacquih@chemistry.leeds.ac.uk) matics generally showed good agreement. Comparison of the concentrations observed by $\mathrm{GC} \times \mathrm{GC}$ to concentrationtime profiles simulated using the Master Chemical Mechanism, MCMv3, demonstrates that this mechanism significantly over-predicts the concentrations of many product compounds and highlights the uncertainties which exist in our understanding of the atmospheric oxidation of aromatics.

\section{Introduction}

Aromatic hydrocarbons are emitted into the atmosphere via automobile emissions and solvent use and represent a significant source of ozone, photo-chemical smog and secondary organic aerosol formation (Derwent et al., 1996). The reactions of these compounds are extremely complex with numerous reaction pathways and a large number of possible products, most of which are also photo-active. The understanding of the details of the atmospheric chemistry of aromatic hydrocarbons has greatly increased in recent years, and the available literature has recently been summarised (Calvert et al., 2002). However significant uncertainties remain, and in particular, the compounds formed by opening of the aromatic ring remain elusive to detection.

It is important to determine the alkylbenzene reaction mechanisms to ensure a sound scientific basis for computational models of the atmosphere. Such models are useful tools to aid understanding of the complex chemistry of the atmosphere, and are used to inform policy decisions concerning issues such as pollution controls. For example, the Master Chemical Mechanism (MCM) has been used in a 
photochemical trajectory model to describe regional ozone formation from the oxidation of emitted hydrocarbons in a European context (Derwent et al., 1998). The relative importance of each hydrocarbon to ozone production is determined by calculation of a photochemical ozone creation potential (POCP) index, which can be used to identify appropriate target compounds for ozone control strategies. The reliability of these calculations is dependent on an accurate representation of the chemical mechanisms.

A common method of investigating photo-oxidation mechanisms is the use of a smog chamber. Concentrations of analytes in the chamber, such as $\mathrm{NO}_{\mathrm{y}}$, the parent VOC and products can be determined accurately both before the chamber is exposed to light and during the photo-oxidation, and thus the degradation of the parent compound and the evolution of products can be monitored. Experiments were carried as part of the EXACT project (Effects of the Oxidation of Aromatic Compounds in the Troposphere), a multidisciplinary study, using a combination of laboratory and chamber experiments in conjunction with modelling studies aimed at elucidating the key features of aromatic oxidation in the atmosphere.

In this paper we describe the application of $\mathrm{GC} \times \mathrm{GC}$ to the identification of products from the photo-oxidation of alkylbenzenes in smog chamber studies. The reactions produce many products at low concentrations, including a large number of carbonyl-type compounds. Suspected intermediates, determined from previous studies and reaction modelling, have widely varying properties and stabilities, making detection by conventional methods difficult. A number of studies have reported carbonyl formation using derivatization followed by GC-MS or HPLC (Dumdei et al., 1988; Smith et al., 1999). This technique is subject to errors due to both sampling inefficiency and the indirect nature of the method. A recent development in high complexity mixture analysis is comprehensive gas chromatography $(\mathrm{GC} \times \mathrm{GC})$, a hyphenated chromatographic technique that offers greatly increased resolution and sensitivity (Liu and Phillips, 1991). Two chromatographic columns of different selectivities, are coupled in series via a mid-point interface. Thus each component of a mixture undergoes two independent orthogonal separations giving a product relation of the two columns respective peak capacities. The ability of $\mathrm{GC} \times \mathrm{GC}$ to separate analytes that co-elute with conventional methodologies makes this technique ideal for the analysis of complex mixtures. $\mathrm{GC} \times \mathrm{GC}$ also provides increased sensitivity over single dimensional chromatography, which is a significant advantage when a large number of low concentration species are present.

\section{Experimental Design}

The MCM is a near-explicit chemical mechanism developed to describe, in detail, the tropospheric degradation of emitted VOC, and is suitable for use over a wide range of atmo- spheric conditions. The current version of the MCM, version 3 (available on the web at http://www.chem.leeds.ac. uk/Atmospheric/MCM/mcmproj.html) is the first to include aromatic degradation mechanisms constructed according to a rigorous and detailed protocol (Jenkin et al., 2003). This has been made possible by the large number of laboratory studies on the atmospheric oxidation of aromatic hydrocarbons in recent years (Calvert et al., 2002), and the consequent improvement in the understanding of the detailed chemistry of these compounds. However, significant uncertainties remain, particularly in the "ring-opening" routes and further development of the mechanisms is required. A schematic of the degradation mechanism of toluene implemented in MCMv3 is shown in Fig. 1 with the species targeted in this study highlighted. Benzaldehyde is the first generation reaction product formed by $\mathrm{H}$-abstraction from the methyl group while the other products are formed following sequential addition of $\mathrm{OH}$ and $\mathrm{O}_{2}$ to the aromatic ring. The well-established phenol type products are formed by elimination of $\mathrm{HO}_{2}$. $p$-Methyl-benzoquinone has been observed as a product of toluene oxidation and in this mechanism is a second generation product in the minor 1,4-addition route. The remaining pathways stem from the chemistry of the 1,2hydroxycyclohexadienyl peroxy radical. The furanones and $\gamma$-dicarbonyl compounds are proposed co-products of glyoxal and methylglyoxal formed as primary products from the decomposition of a peroxide-bicyclic radical, and maleic anhydride and citraconic anhydride are formed in the oxidation of the $\gamma$-dicarbonyl compounds. Epoxy-type products have also been proposed as aromatic oxidation products, and support for their formation has been provided by GC-MS experiments (Yu and Jeffries, 1997). However, positive confirmation and quantification of these products requires standards and has not yet been achieved. The epoxy route which proceeds by formation and subsequent decomposition of an cyclic epoxy-oxy radical, is included in the mechanism to represent the balance of the chemistry not accounted for by other routes.

Detailed aromatic degradation mechanisms were used to design experiments aimed at the creation of a high quality data set to test the details of the mechanism and facilitate mechanism development. Details of these calculations have been published previously (Wagner et al., 2003) and only a brief summary of the results relevant to this study is given here.

The $\mathrm{OH}$ budget has been calculated for the oxidation of toluene under conditions appropriate for a comparison with a EUPHORE chamber experiment carried out in 1997. It has been shown that the primary product in the epoxy route and the co-products of glyoxal and methylglyoxal are important radical sources accounting for about $15 \%$ and $25 \%$ respectively of the newly produced $\mathrm{OH}$ over the course of the experiment and are particularly important in the early stages of the experiment. The yields and photochemistry of these products is highly uncertain and analysis of the discrepancies 


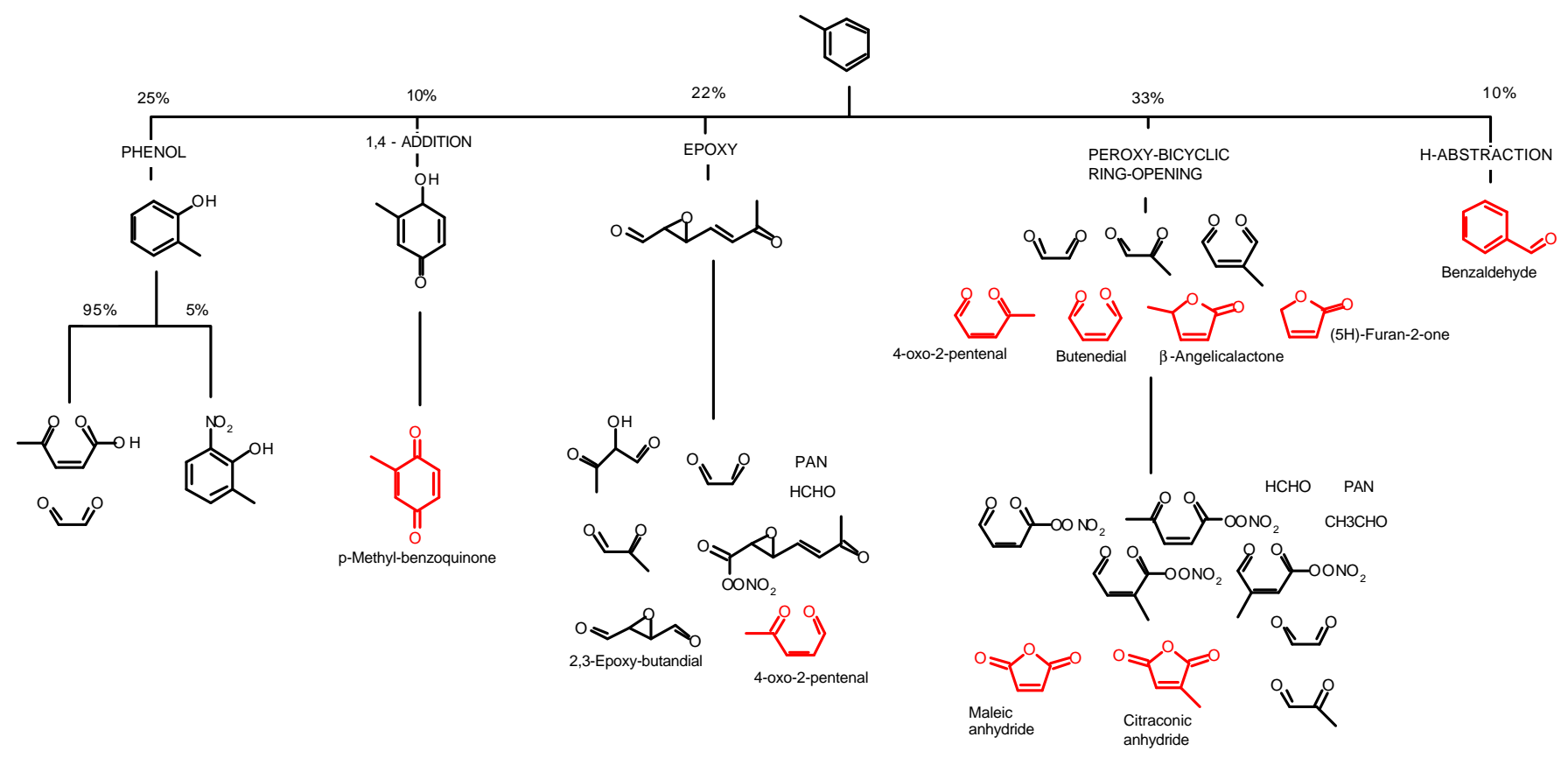

Fig. 1. Schematic of degradation mechanism of toluene as implemented in MCMv3.

between modelled and measured $\mathrm{OH}$ production suggests that these areas of the mechanism are likely to be responsible for these observed discrepancies. The sensitivity of ozone production to the yields of various products was also investigated and it was shown that ozone has the highest sensitivities to changes in the concentrations of epoxide compounds, $\gamma$-dicarbonyls and methylglyoxal, while it is relatively insensitive to the yield of cresol, formaldehyde, glyoxal and benzaldehyde. Hence, the identification and quantification of the co-products of glyoxal and methylglyoxal, and the major products in the proposed epoxy route, are very important for improvement of the toluene mechanism, and these are the main species targeted in this $\mathrm{GC} \times \mathrm{GC}$ study.

Analogous pathways exist for the other aromatics and the full list of targeted intermediates for this study is given in Table 1. This list also includes some species not currently represented in the mechanisms but postulated as alternative products in the routes described above or as products in alternative routes. In addition some compounds were investigated as models for intermediates which were unavailable. For example, it has been suggested that the photo-oxidation of aromatics has a reaction channel proceeding via aromatic oxide/oxepin intermediates (Klotz et al., 1997; Klotz et al., 2000), with muconaldehydes as ring-opening products. Toluene-oxide and 6-oxo-2,4-heptadiendial are targeted species to test for this route in the toluene experiments. The proposed product 2,3-epoxy-butandial could not be synthesised but the related compound 2,3-epoxy-butanal was made instead, and included as a target species as a model for similar products in the epoxy route. Analyte structures are available in Appendix 1.
The initial conditions for the experiments were carefully chosen to maximise the useful information available. It has been shown (Wagner et al., 2003) that the sensitivity of ozone production to model parameters (e.g. rate coefficients, product yields, photolysis rates) is highest at low $\mathrm{VOC} / \mathrm{NO}_{\mathrm{x}}$ ratios, i.e. where the ozone production is limited by the availability of VOC, and therefore experiments at low $\mathrm{VOC} / \mathrm{NO}_{\mathrm{x}}$ ratios are particularly suited to identify shortcomings of the ozone chemistry in models. However, it is important that the mechanisms are also tested under $\mathrm{NO}_{\mathrm{x}}$ limited conditions, and so experiments were carried out at both low and high $\mathrm{VOC} / \mathrm{NO}_{\mathrm{x}}$ ratios. Model simulations were used to generate isopleth plots of ozone production as a function of initial $\mathrm{NO}_{\mathrm{x}}$ and VOC concentrations and VOC and $\mathrm{NO}_{\mathrm{x}}$ limited regimes could be identified, as discussed by Wagner et al. (2003). Unfortunately the VOC limited region is not experimentally accessible for p-xylene and 1,3,5trimethylbenzene as the concentration of the aromatic is either too low for accurate measurements, or the $\mathrm{NO}_{\mathrm{x}}$ concentration is so high $(>500 \mathrm{ppb})$ that it can significantly affect the branching ratio between ring-opening and ring-retaining routes (Volkamer et al., 2002). It was also possible to carry out experiments at constant and low $\mathrm{NO}_{\mathrm{x}}$ concentrations typical of conditions in rural and suburban environments (less than $10 \mathrm{ppb}$ ) by injection of an $\mathrm{NO} / \mathrm{NO}_{2} / \mathrm{HONO}$ mixture controlled by a feedback mechanism. The initial conditions for all the experiments included in this study are shown in Table 2 . 
Table 1. Full list of targeted intermediates for which liquid calibration standards were used. Analytes unavailable commercially are indicated and were synthesised as described in the text.

\begin{tabular}{lll}
\hline Peak & Proposed intermediate & $\begin{array}{l}\text { Available } \\
\text { commercially }\end{array}$ \\
\hline 1 & 2,3-Epoxy-butanal & No \\
2 & Z-butenedial & No \\
3 & $E$-butenedial & No \\
4 & (3H)-Furan-2-one & No \\
5 & Maleic anhydride & Yes \\
6 & 2-Furaldehyde & Yes \\
7 & $\alpha$-Angelicalactone & Yes \\
8 & (5H)-Furan-2-one & Yes \\
9 & $\gamma$-Angelicalactone & No \\
10 & $\beta$-Angelicalactone & No \\
11 & $Z$-hexene-2,5-dione & No \\
12 & Benzaldehyde & Yes \\
13 & $p$-Methyl-benzoquinone & Yes \\
14 & Toluene-oxide & No \\
15 & 6-Oxo-2,4-heptadienal & No \\
16 & Citraconic anhydride & Yes \\
& E-4-oxo-2-pentenal & No \\
& Z-4-oxo-2-pentenal & No \\
& $E$-hexene-2,5-dione & No \\
& 3,5-Dimethyl-benzaldehyde & Yes \\
& 2,4,6-Trimethyl-phenol & Yes \\
& 3-Methyl-5-methylene-5H-furan-2-one & No \\
& 3,5-Dimethyl-5H-furan-2-one & No \\
& 3,5-Dimethyl-3H-furan-2-one & No \\
\hline & &
\end{tabular}

\section{Experimental}

\subsection{European Photo-Reactor (EUPHORE)}

EUPHORE is a large volume outdoor photochemical reaction chamber located in Valencia, Spain, and consists of two FEP-Teflon hemispheres, each with a volume of approximately $200 \mathrm{~m}^{3}$. The chambers are equipped with numerous analytical instruments, the floor is water-cooled to minimise solar heating of the chamber during experiments, and an air purification and drying system provides $\mathrm{NO}_{\mathrm{y}^{-}}$, NHMC-free, and dry air, while two fans ensure homogenous mixing of the chamber air. A hydraulically controlled steel housing protects the chamber from sunlight and the weather when it is not in use. The chamber used for the experiments in this study is equipped with gold-coated mirrors forming a White-type multireflection cell coupled to an FTIR interferometer (NICOLET Magna 550, MCT-B detector) for in situ measurements. The FTIR was operated at an absorption path length of $326.8 \mathrm{~m}$, and a spectral resolution of $1 \mathrm{~cm}^{-1}$. The spectra were derived from the co-addition of 570 interferograms, with a time resolution was $10 \mathrm{~min}$. The FTIR spectra were analysed by subtracting individual reference spectra to obtain the concentration of those compounds. A detailed description of the EUPHORE can be found in the literature (Becker, 1996; Klotz et al., 1998).

In each experiment, a small quantity of the aromatic compound under investigation was introduced into the dark chamber using a calibrated syringe. The initial concentrations of all reactants are shown in Table 2. NO was introduced from a gas cylinder via a Teflon transfer line. The chamber contents were allowed to mix for at least $30 \mathrm{~min}$ before opening the protective covers and exposing the chamber to sunlight. The decay of the parent aromatic and the evolution of products was monitored using $\mathrm{GC} \times \mathrm{GC}$. A dark experiment using 2,3-dimethyl-2-butene as an $\mathrm{OH}$ source and a replacement NO experiment, where the NO level is kept constant, were also carried out for 1,3,5-trimethylbenzene.

\section{2 $\mathrm{GC} \times \mathrm{GC}$ technique}

A HP 6890 Gas Chromatograph (Agilent Technologies, Wilmington, DE, USA) equipped with a flame ionisation detector capable of operation at $200 \mathrm{~Hz}$ was fitted with a microactuated 10 port rotary valve (Valco International, Schenkon, Switzerland). The valve was housed within the GC oven and thus the valve temperature tracked the ambient oven temperature. A $10 \mu$ l Silcosteel sample loop (Valco International, Schenkon, Switzerland) was used giving good sensitivity and reproducible results. The valve was controlled using software written "in house" which controls the sampling and sweep time. The sampling interval was $3.8 \mathrm{~s}$ and the time to flush the loop contents onto the second column was $350 \mathrm{~ms}$.

The column set used to detect the carbonyl compounds was:

1st dimension column: $50 \mathrm{~m} \times 320 \mu \mathrm{m} \times 4 \mu \mathrm{m}$ BP-1 (SGE, Ringwood, Australia)

2nd dimension column: $0.6 \mathrm{~m} \times 100 \mu \mathrm{m} \times 0.1 \mu \mathrm{m}$ BP-20 (SGE, Ringwood, Australia)

The very short second column, with a highly polar stationary phase, was vital to ensure both good second dimension separation and narrow peak shapes. The carrier gas used was hydrogen (99.999\% purity, Praxair, Madrid, Spain). Cryofocusing of analytes prior to injection was carried out using a six port valve and a stainless steel sample loop held above liquid nitrogen. Two litres of chamber air were sucked through the loop, at $-140^{\circ} \mathrm{C}$, and then desorbed by heating at $60^{\circ} \mathrm{C}$. This sampling system can cause inefficient trapping for very polar compounds. Therefore, glyoxal, methyl glyoxal and phenol could not be measured using this method. The modulator allowed independent carrier gas flow rate regulation of both columns. For chamber experiments, hydrogen flow rates were $15 \mathrm{ml} \mathrm{min}^{-1}$ for 30 seconds, reducing to $5 \mathrm{ml} \mathrm{min}{ }^{-1}$ on the primary column and a constant $5 \mathrm{ml} \mathrm{min}^{-1}$ on the secondary column. The increased initial flow through the pre-concentration loop ensures that a narrow plug of sample was delivered onto the head of the primary column.

Liquid calibration standards were made in HPLC grade acetonitrile (Reidel-de Haën, Seelze, Germany). High purity 
Table 2. Initial conditions for EUPHORE experiments.

\begin{tabular}{|c|c|c|c|c|}
\hline \multirow[t]{2}{*}{ Date } & \multirow[t]{2}{*}{ Parent aromatic } & \multicolumn{2}{|c|}{ Initial Concentration (ppb) } & \multirow[t]{2}{*}{ Notes } \\
\hline & & aromatic & $\mathrm{NO}_{\mathrm{x}}$ & \\
\hline $09 / 07 / 2002$ & Benzene & 1014 & 182 & High $\mathrm{NO}_{\mathrm{x}}$, VOC limit \\
\hline $25 / 09 / 2001$ & Toluene & 512 & 474 & High $\mathrm{NO}_{\mathrm{x}}$, VOC limit \\
\hline $27 / 09 / 2001$ & Toluene & 496 & 144 & Moderate $\mathrm{NO}_{\mathrm{X}}, \mathrm{NO}_{\mathrm{X}}$ limit \\
\hline 03/07/2002 & $p$-xylene & 553 & 142 & Moderate $\mathrm{NO}_{\mathrm{X}}, \mathrm{NO}_{\mathrm{X}}$ limit \\
\hline $17 / 09 / 2001$ & $1,3,5-\mathrm{TMB}$ & 285 & $5-7$ & Replacement $\mathrm{NO}_{\mathrm{X}}, \mathrm{NO}_{\mathrm{X}}$ limit \\
\hline $21 / 09 / 2001$ & $1,3,5-\mathrm{TMB}$ & 446 & 96 & Low $\mathrm{NO}_{\mathrm{X}}, \mathrm{NO}_{\mathrm{X}}$ limit \\
\hline $26 / 09 / 2001$ & $1,3,5-\mathrm{TMB}$ & 272 & 284 & Moderate $\mathrm{NO}_{\mathrm{X}}, \mathrm{NO}_{\mathrm{X}}$ limit \\
\hline $28 / 09 / 2001$ & $1,3,5-\mathrm{TMB}$ & 440 & 1.5 & Dark experiment \\
\hline
\end{tabular}

reagents were obtained from Sigma-Aldrich (Gillingham, UK). Analytes unavailable commercially were synthesised and are indicated in Table 1.

\subsection{Synthesis of commercially unavailable chemicals}

$E$-Butendial was obtained from the acid hydrolysis of $E$ 1,1,4,4-tetramethoxybutene with amberlyst-15 in moderate yield (Nadkarni and Sayre, 1995). Oxidation of 2methylfuran gave Z-4-oxo-2-pentenal in good yield using either dimethyl dioxirane in acetone or $m$-chloroperbenzoic acid as the oxidant (Adger et al., 1991). Hex-3-ene-2,5-dione was obtained in the same way from 2,5-dimethylfuran as a mixture of the $E$-and $Z$-isomers (2:3) in excellent yield (Adger et al., 1991). Any further attempts at purification increased the proportion of the $E$-isomer. Bromination of 2-methylfuran in methanol and subsequent aqueous hydrolysis gave E-4-oxo-2-pentenal (Xu et al., 1999). Hydrogen peroxide oxidation of crotonaldehyde in dichloromethane gave 2,3-epoxybutanal in good yield (Ceroni and Sequin, 1982). Oxidation of 2-furaldehyde with performic acid, generated from formic acid and hydrogen peroxide, yielded $(3 \mathrm{H})$-furanone in moderate yield (Nasman and Pensar, 1985).

Synthesis of 5-methyl-5H-furan-2-one $\quad(\beta$ Angelicalactone) was achieved by the isomerisation of $\alpha$-angelicalactone using triethylamine $(1.0 \mathrm{ml})$ Purification by preparative gas chromatography yielded the product as a colourless oil in good yield (Thiele et al., 1901). 5-Methylene-dihydro-furan-2-one ( $\gamma$-Angelicalactone) was obtained in two steps from 4-pentenoic acid. Essentially, iodination of the acid gave 5-iodomethyl-dihydrofuran-2-one in excellent yield. Subsequent elimination with 1,8-diazabicyclo[5.4.0]undec-7-ene (DBU) gave $\gamma$ angelicalactone in moderate yield (Gunther et al., 1984). 3-Methyl-5-methylene-dihydro-furan-2-one was obtained in excellent yield using the same method with 2-methylpenten-4-enoic acid as the starting material (Gunther et al., 1984).

3,5-Dimethyl-(3H)-furan-2-one and 3,5-Dimethyl-(5H)furan-2-one were obtained after three steps starting from ethyl acetoacetate. Deprotonation of ethyl acetoacetate and subsequent reaction with ethyl 2-bromopropionate gave 2acetyl-3-methyl-succinic acid diethyl ester, which after acid hydrolysis yielded 2-methyl-4-oxopentanoic acid. Cyclisation of 2-methyl-4-oxopentanoic acid with phosphoric acid and subsequent chromatography resulted in two fractions, the first of which was the $(3 \mathrm{H})$-furan-2-one derivative, and the second of which was the $(5 \mathrm{H})$-furanone derivative, both in poor yield (Torii et al., 1983). 3-Methyl-5-methylene-5Hfuran-2-one was obtained from the reaction of 2-methyl-4pentenoic acid with acetyl chloride and conc. sulphuric acid. Chromatography gave the product in poor yield (Buchta and Satzinger, 1995).

Benzene oxide, toluene oxide, Z,Z-muconaldehyde and Z,Z-6-oxo-hepta-2,4-dienal were synthesised according to (Bleasdale et al., 1997). Essentially, the appropriate 1,4cyclohexadiene was reacted with 1 equivalent of bromine to give a trans-4,5-dibromocyclohex-1-ene, which was epoxidized to the trans-4,5-dibromocyclohex-1-ene oxide, a stable and convenient precursor of arene oxide-oxepins. Treatment of the trans-4,5-dibromocyclohex-1-ene oxide with an excess of DBU gave highly pure arene oxide-oxepin after fractional distillation. Dimethyl dioxirane oxidation of the arene oxide-oxepin gave the corresponding dienedial as their Z,Z-isomers.

\section{Results and Discussion}

The reactions were carried out during the EXACT (Effects of the Oxidation of Aromatic Compounds in the Troposphere) campaigns in September/October 2001 and July 2002. Two litre air samples were injected every thirty minutes and a $\mathrm{GC} \times \mathrm{GC}$ chromatogram obtained. The series of short second dimension chromatograms were converted into a matrix reflecting the retention times on columns 1 and 2 and the intensity of the signal. The data was then plotted as a coloured contour plot. Chromatograms obtained for a typical standard mixture and a chamber sample are shown in Fig. 2. Each spot represents an analyte and identification is based on the retention behaviour of the standard mixtures. The second 

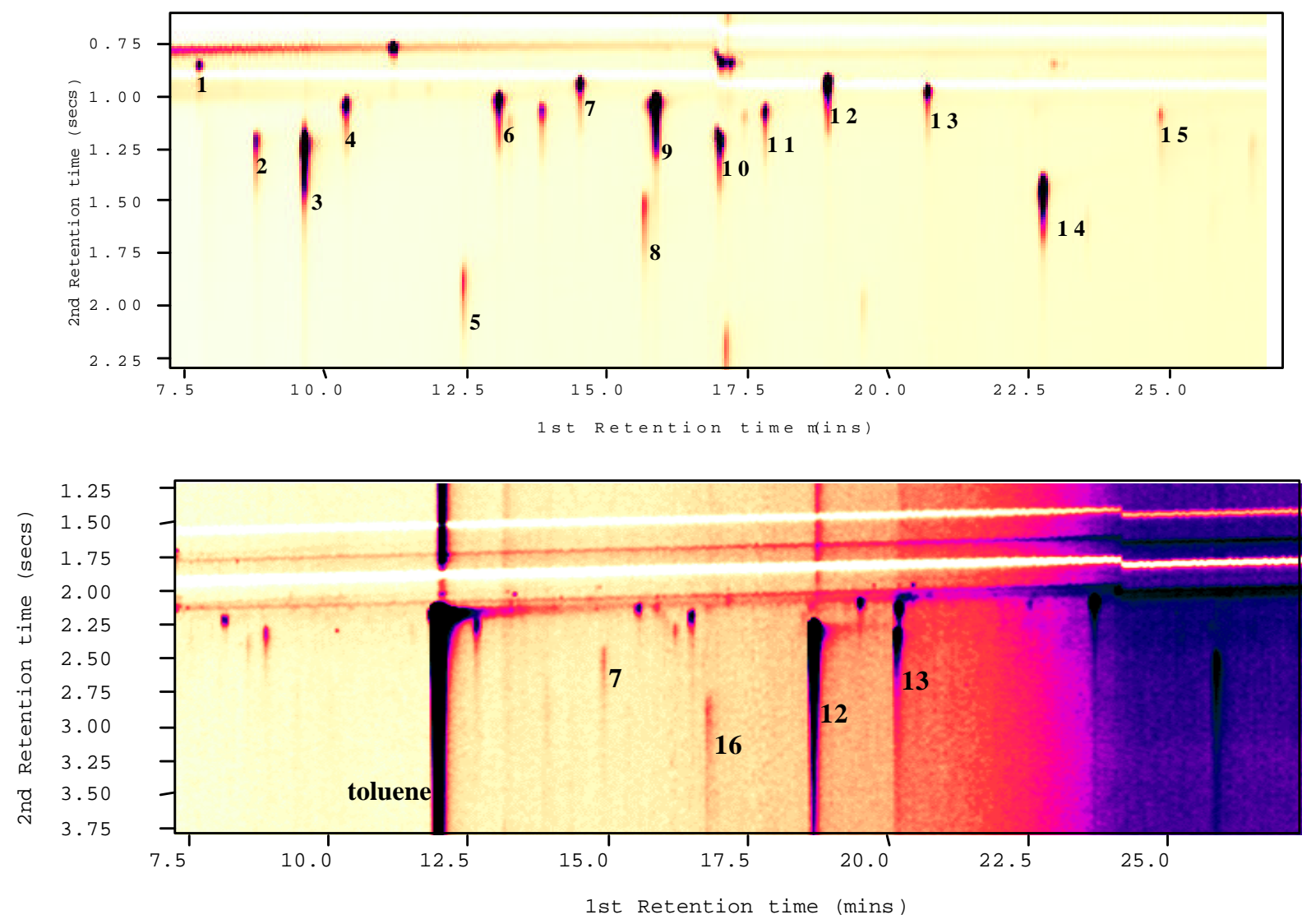

Fig. 2. Chromatograms for a typical standard mixture and a chamber sample.

dimension separation is based on polarity and thus the position of the spot on the second dimension gives an indication of the type of species present. The complete list of carbonyl liquid standards which have been studied using $\mathrm{GC} \times \mathrm{GC}$ are shown in Table 1. Species observed during smog chamber studies of the four parent aromatics are shown in Table 3. Positive confirmation of the position of each compound on this $2 \mathrm{D}$ plane was made using $\mathrm{GC} \times \mathrm{GC}-\mathrm{TOF} / \mathrm{MS}$ measurements.

Calibration of the $\mathrm{GC} \times \mathrm{GC}$ system for stable hydrocarbons, i.e. the parent aromatics, was made with reference to certified gas standards at the ppb level (National Physical Laboratory, Teddington, UK). Typical single column GCFID instruments may have relative standard deviations of the order of $0.2-0.8 \%$ for this type of measurement, with an overall level of uncertainty at the single figure $\%$ level arising mainly from gravimetric errors associated with the preparation of standards. The two column $\mathrm{GC} \times \mathrm{GC}$ approach produces slightly more scattered data rsd $\sim 5-8 \%$ due to distribution in peak maxima position and subsequent cone fitting generated on sample transfer between columns. This has been discussed theoretically (Lee et al., 2001). However, uncertainty in the preparation of the primary hydrocarbon gas standard is, of course, the same. For carbonyl species cali- bration has been made using the direct injection on column of varying volumes and concentrations of liquid standards. The preparation of gas standard cylinders is clearly not possible for such polar compounds, and the unstable nature of many species make permeation tube calibration also unreliable.

Liquid standards are a far from ideal method of calibration but we consider it is the only method applicable to a chromatography based technique. The run to run reproducibility of liquid standards was of the order 2-9\% rsd. Over the 3 or 4 week period of each campaign the standards were internally consistent. Combination of run to run variability in peak area and errors associated in production of liquid standards is likely to have resulted in errors per species of the order 10$15 \%$. The largest uncertainty however is in the calibration of possible sampling errors, and clearly without gas standards this is very difficult to determine. To account for this we have therefore extended the overall uncertainty of measurement to $50 \%$, to including both errors in calibration (highlighted earlier), in sampling (sample volumes etc), and an estimation of maximum uncertainty generated through sampling steps that we have been unable to test directly with gas standards. This we believe to be very much an upper estimate of the potential uncertainty in the measurements. A series of chamber calibrations were also carried out. A known quantity of a 
Table 3. Intermediates observed during smog chamber experiments including chamber calibrations.

\begin{tabular}{|c|c|c|c|}
\hline \multirow{2}{*}{$\begin{array}{l}\text { Compounds observed } \\
\text { during chamber } \\
\text { experiments }\end{array}$} & \multirow{2}{*}{$\begin{array}{l}\text { Maximum observed } \\
\text { in photosmog } \\
\text { experiments }\end{array}$} & \multicolumn{2}{|c|}{ Chamber Calibration $^{1}$} \\
\hline & & $\begin{array}{l}\text { Actual } \\
(\mathrm{ppb})\end{array}$ & $\begin{array}{l}\text { Measured } \\
\quad(\mathrm{ppb})\end{array}$ \\
\hline \multicolumn{4}{|l|}{ TOLUENE REACTION } \\
\hline E-4-oxo-2-pentenal ${ }^{2}$ & Co-elutes & & \\
\hline Z-4-oxo-2-pentenal ${ }^{2}$ & Co-elutes & & \\
\hline$\alpha$-Angelicalactone ${ }^{2}$ & $0.6 \mathrm{ppb}$ & 19 & 26 \\
\hline$p$-Methyl-benzoquinone & $1 \mathrm{ppb}$ & & \\
\hline Benzaldehyde & $7 \mathrm{ppb}$ & 54 & 58 \\
\hline Maleic anhydride & $1.6 \mathrm{ppb}$ & & \\
\hline Citraconic anhydride & $\begin{array}{l}\text { Not calibrated } \\
\text { area }=0.6\end{array}$ & & \\
\hline $5 \mathrm{H}$-furan-2-one & Not observed & 20 & 19 \\
\hline \multicolumn{4}{|l|}{$p$-XYLENE } \\
\hline E-hexene-dione & $0.3 \mathrm{ppb}$ & & \\
\hline Z-hexene-dione & $0.5 \mathrm{ppb}$ & & \\
\hline Citraconic Anhydride & $\begin{array}{l}\text { Not calibrated } \\
\text { area }=1\end{array}$ & & \\
\hline 1,3,5-TMB REACTION Dimethyl-benzaldehyde & $0.2 \mathrm{ppb}$ & & \\
\hline $\begin{array}{l}\text { 3-Methyl-5-methylene-5H- } \\
\text { furan-2-one }\end{array}$ & $\begin{array}{l}\text { Not calibrated } \\
\text { area }=0.4\end{array}$ & & \\
\hline $\begin{array}{l}\text { 3,5-Dimethyl-5H-furan-2- } \\
\text { one }\end{array}$ & $\begin{array}{l}\text { Not calibrated } \\
\text { area }=5.5\end{array}$ & & \\
\hline 3,5-Dimethyl-3H-furan-2- & Co-elutes with & & \\
\hline one & 1,3,5-TMB & & \\
\hline
\end{tabular}

${ }^{1}$ Calibrations were conducted using liquid standards for all the species that are quantified. In addition, gas phase calibrations were conducted for some of the species in the toluene system.

${ }^{2}$ The $\alpha$-angelicalactone and the $E$ - and $Z$-isomers of 4-oxo-2-pentenal co-elute. We suggest that the 4-oxo-2-pentenal is cyclising to the $\alpha$-angelicalactone during the course of the analysis.

suspected intermediate was introduced into the chamber via a heated gas stream. $\mathrm{GC} \times \mathrm{GC}$ chromatograms were collected and the concentrations determined. The actual and measured concentrations obtained for $\alpha$-angelicalactone, benzaldehyde and $5 \mathrm{H}$-furan-2-one are shown in Table 3 , and we are encouraged by the relatively good agreement. $E$ - and $Z$-butendial were also calibrated in the chamber but results were inconsistent. The method of introducing analytes to the chamber was unsuitable for unstable compounds such as butendial, with isomerisation and degradation of the sample occurring. Ideally, all analytes should be calibrated in the chamber but this was not practical within the time scale of the campaign and the analytes calibrated are assumed to be representative of all analytes.

Model simulations were carried out for all the experiments in this study using the aromatic mechanisms of MCMv3. The simulations were initialised with the measured initial concentrations of the parent aromatic, $\mathrm{NO}$ and $\mathrm{NO}_{2}$. The photolysis rates calculated in the MCM were scaled to the measured $\mathrm{NO}_{2}$ photolysis rate and the measured chamber tem- perature and humidity were also used as parameters in the models. An auxiliary mechanism was included to account for chamber related effects such as the introduction of free radicals through wall reactions, the absorption/desorption of $\mathrm{NO}_{\mathrm{y}}$ species on/from the walls, and the dilution of compounds during the experiments caused by the continuous addition of air to compensate for losses from sampling and leaks. The simulated concentrations can then be compared to those measured in order to test our understanding of the degradation chemistry of aromatic hydrocarbons. The estimated error limits on the simulated concentrations, shown in the figures as shaded grey areas, were calculated by varying the loss rates of each species in individual model runs as indicated in Table 4, and for angelicalactone/4-oxo-2-pentenal the error shown is the sum of the errors calculated for each component. 
Table 4. Loss rates of target species varied to estimate error limits on simulated concentrations.

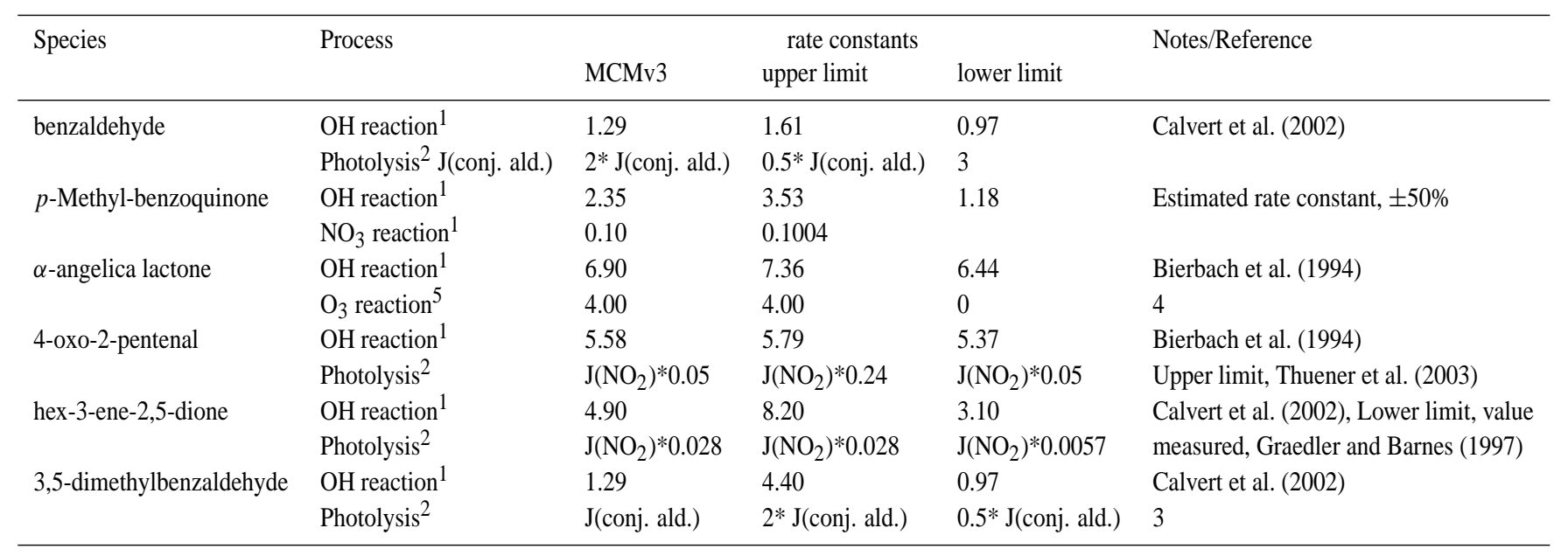

${ }^{1}$ Rate constant units are $10^{-11}$ molecule ${ }^{-1} \mathrm{~cm}^{3} \mathrm{~s}^{-1}$

${ }^{2}$ Rate constant units are $\mathrm{s}^{-1}$

${ }^{3}$ Photolysis rate calculated for $\mathrm{CH}_{2}=\mathrm{C}\left(\mathrm{CH}_{3}\right) \mathrm{CHO}$ and applied to related species, (Saunders et al., 2002)

${ }^{4} \mathrm{MCMv} 3$ uses high rate constant, set to zero as a lower limit to examine effect of this reaction

${ }^{5}$ Rate constant units are $10^{-17}$ molecule ${ }^{-1} \mathrm{~cm}^{3} \mathrm{~s}^{-1}$

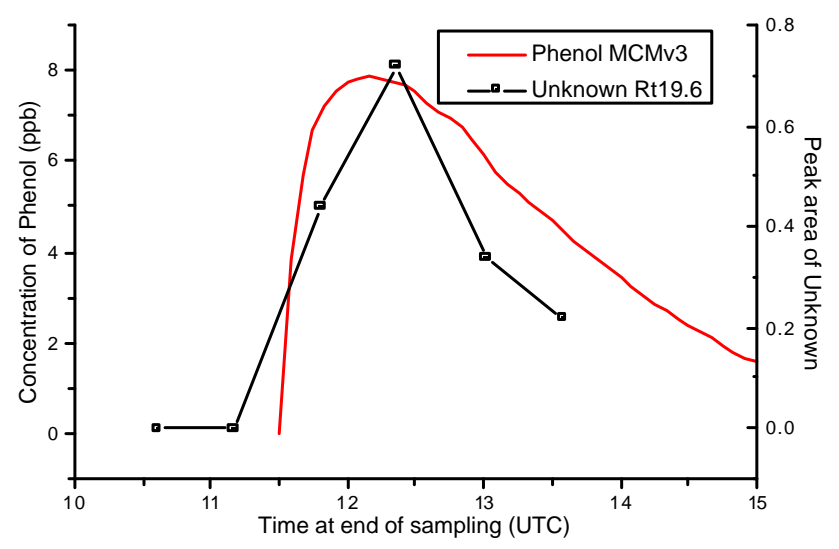

Fig. 3. Experimentally observed concentration-time profiles for unknown compound and model simulations in the benzene high $\mathrm{NO}_{\mathrm{x}}$ experiment (09/07/02).

\subsection{Benzene Oxidation Products}

During the photo-oxidation of benzene in the chamber only one product was apparent in the $\mathrm{GC} \times \mathrm{GC}$ chromatogram and the time series is shown in Fig. 3. This peak did not correspond to any of the intermediates under investigation so the structure is not known. Expected products of benzene oxidation for which standards have been studied are butenedial, $5 \mathrm{H}$-furan-2-one and maleic anhydride, and the predicted peak concentrations of these compounds in the experiment are $4.4 \mathrm{ppb}, 3.4 \mathrm{ppb}$, and $5.6 \mathrm{ppb}$. The predicted peak concentration of 2,3-epoxybutandial was $1.4 \mathrm{ppb}$, but based on the behaviour of the related compound 2,3-epoxybutanal, it is not thought to be the unknown. As the detection limit of polar oxygenated species is approximately $0.1 \mathrm{ppb}$ using this $\mathrm{GC} \times \mathrm{GC}$ system it appears that the model significantly overpredicts the concentrations of these product species. The unknown peak has a similar retention time to benzene-oxide on the volatility separation but is of higher polarity, being more strongly retained on column 2 . We hypothesis that this peak may be phenol, as it is also present in the benzene-oxide liquid standard, where it is a known reaction by-product. The analyte has a maximum concentration after $90 \mathrm{~min}-$ utes with a maximum response of 0.8 (calibration using $\alpha$ angelicalactone gives concentration of about $1 \mathrm{ppb}$ ). Phenol will not trap well with the method used here, so the result will be subject to large errors. Model simulations with the MCMv3 mechanism predict a peak concentration of $8 \mathrm{ppb}$ for phenol in the chamber experiment, as shown in Fig. 3, though there is some evidence that the phenol channel yield of $25 \%$ used in the mechanism may be too low (Volkamer et al., 2002), and the peak concentration of phenol measured during this experiment by HPLC was $13.5 \pm 4.1 \mathrm{ppb}$.

\subsection{Toluene Oxidation Products}

Five products from the photochemical oxidation of toluene were detected and identification was made from standard mixtures. Both "ring retained" products (benzaldehyde and 

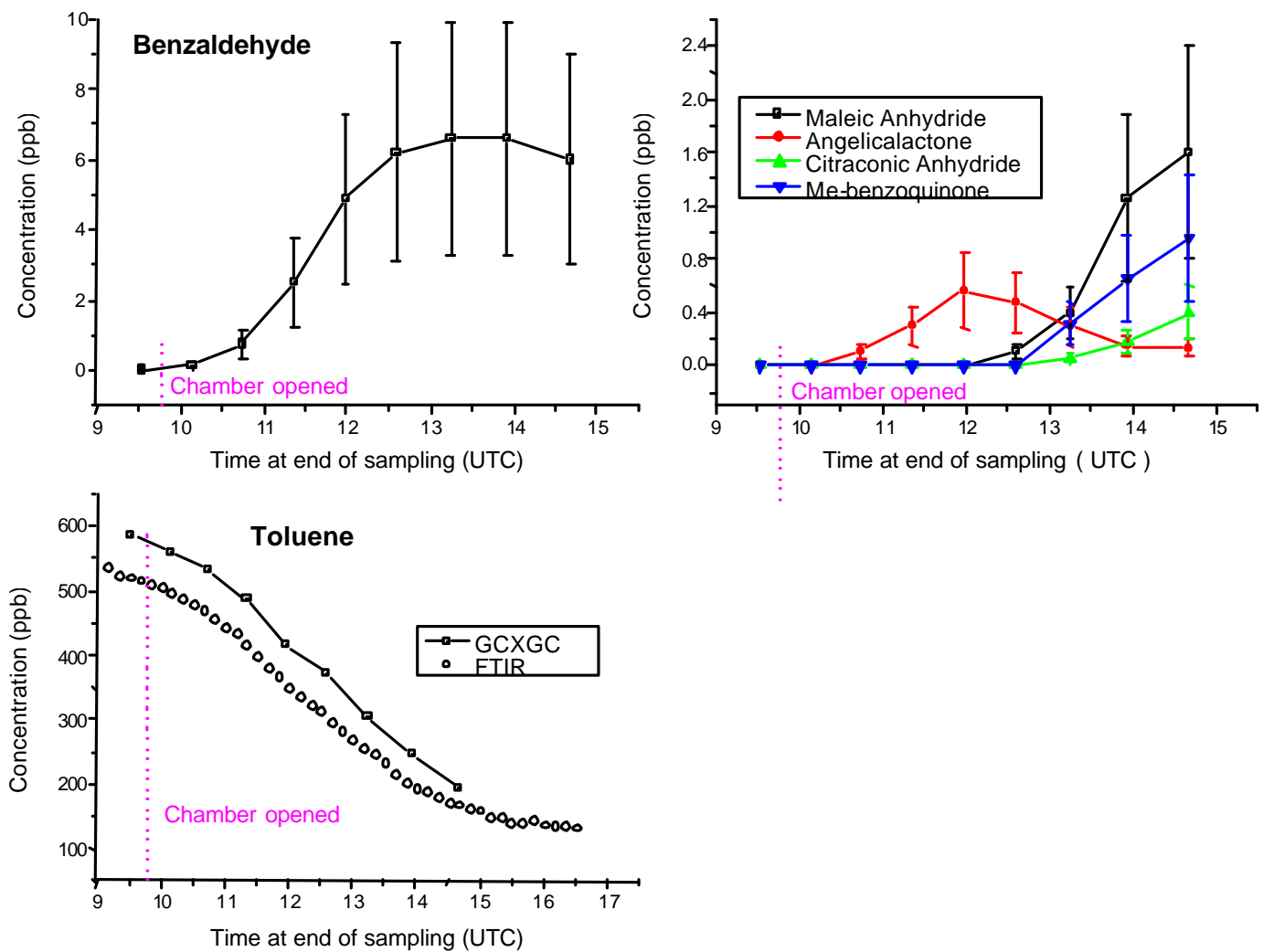

Fig. 4. Experimentally observed concentration-time profiles for parent compound and intermediates in the toluene high $\mathrm{NO}_{\mathrm{x}}$ experiment $(25 / 09 / 01)$. Error limits on the concentrations of intermediates are $\pm 50 \%$. Toluene, benzaldehyde, angelicalactone, methyl benzoquinone and maleic anhydride are quantified by liquid standard calibration and citraconic anhydride peak areas are presented to show their time dependent behaviour. The concentration of the parent compound obtained by $\mathrm{GC} \times \mathrm{GC}$ is compared to FTIR measurements and shows reasonable agreement.

$p$-methylbenzoquinone) and "ring cleaved" products (maleic anhydride, citraconic anhydride and $\alpha$-angelicalactone/4oxo-2-pentenal) were observed. $\alpha$-Angelicalactone and the $E$ - and $Z$-isomers of 4-oxo-2-pentenal co-elute using the column set described here. However, a series of second dimension columns were tested and co-elution occurred under all conditions. We suggest that 4 -oxo-2-pentenal cyclises to $\alpha$ angelicalactone during the course of the analysis. An advantage of $\mathrm{GC} \times \mathrm{GC}$ is the ability to observe directly the evolution of the carbonyl-type products over the course of the reaction. The results obtained for the high $\mathrm{NO}_{\mathrm{x}}$ reaction on the 25 September 2001 are shown in Fig. 4. The analysis time is thirty minutes, allowing between four and eight samples to be taken per experiment. Even with this low sampling frequency the growth and consumption of products in the reaction are clearly observed. A comparison of the concentrations of toluene obtained by GC $\times$ GC and FTIR is also shown and the decay curves are the same shape with an apparent positive offset of about $50 \mathrm{ppb}$ seen for the $\mathrm{GC} \times \mathrm{GC}$ method at shorter times. Owing to the lack of gas standards, $\mathrm{GC} \times \mathrm{GC}$ calibrations were obtained using liquid standards.
Toluene photosmog experiments were conducted with initial concentrations of $474 \mathrm{ppb}$ and $144 \mathrm{ppb} \mathrm{NO}_{\mathrm{x}}$. Figure 5 shows a comparison of the results obtained from experiment with the concentrations predicted by the MCMv3 simulations. The model simulations are shown as solid black lines; in the case of the angelicalactone/4-oxo-2-pentenal pair the solid line is the sum of the two component species with the dotted lines showing the concentrations of the individual compounds. As shown in Fig. 1, MCMv3 includes $\beta$ angelicalactone as a product rather than $\alpha$-angelicalactone, and it is the simulation for this $\beta$-form that is shown in Fig. 5. $\beta$-Angelicalactone was a target species but is not observed in these experiments, and it appears that any angelicalactone product is of the $\alpha$-form. $\alpha$-Angelicalactone has also been observed as a product of toluene degradation in previous work (Smith et al., 1998), and ongoing development of the MCM will incorporate this product.

It is clear to see that the maximum concentration of carbonyl-type products are delayed in the VOC limited experiments when compared to the moderate $\mathrm{NO}_{\mathrm{x}}, \mathrm{NO}_{\mathrm{x}}$ limited regime, both in the simulations and the experimental observations. The only product observed experimentally in 
high NOx - 25/09/01
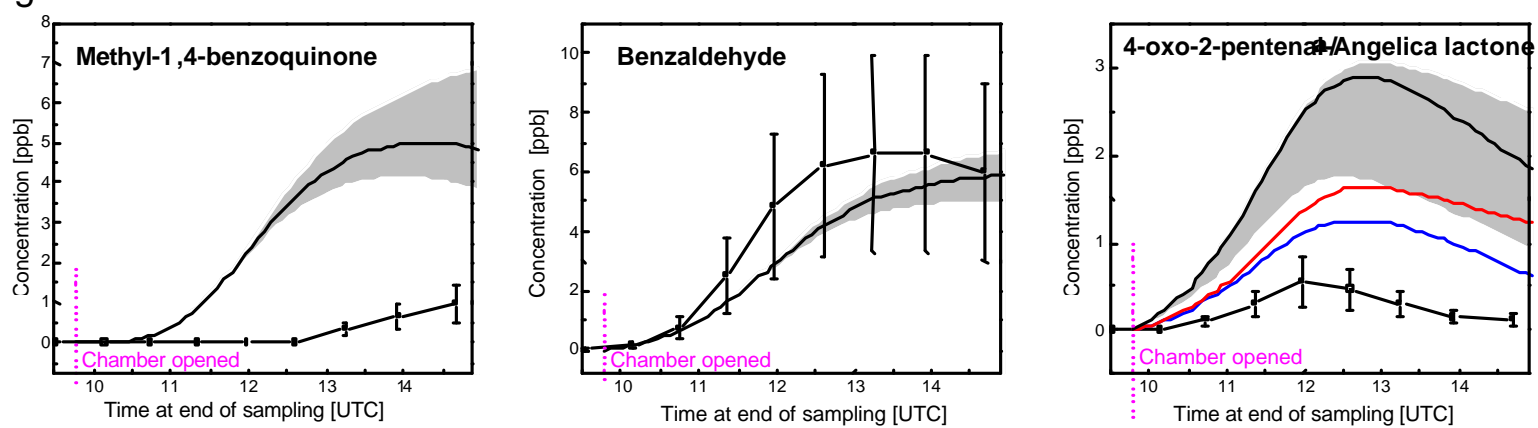

moderate NOx - 27/09/01
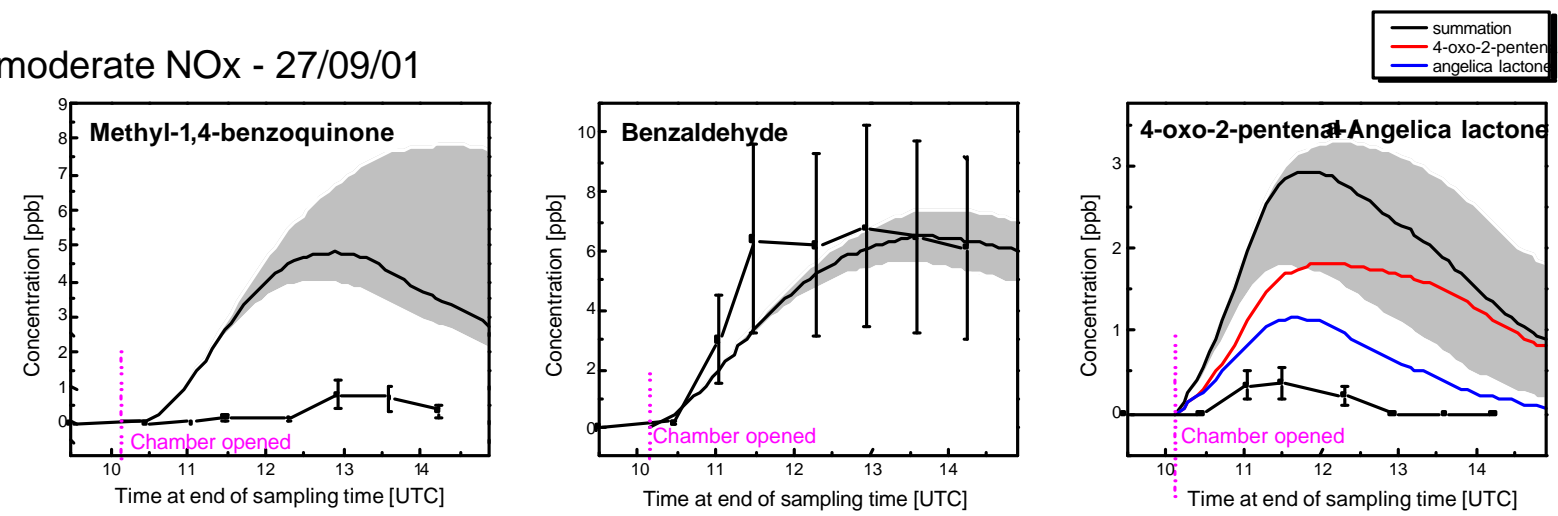

Fig. 5. Comparison of experimental results and simulations for intermediates in the toluene high $\mathrm{NO}_{\mathrm{x}}(25 / 09 / 01)$ and moderate $\mathrm{NO}_{\mathrm{x}}$ $(27 / 09 / 01)$ experiments. Error limits on the experimental points are $\pm 50 \%$ and the estimated error on the simu lations shown as shaded grey areas were calculated by varying the loss rates of each species in individual model runs as indicated in Table 4 .

appreciable quantities is benzaldehyde, a ring retained product formed by $\mathrm{H}$-abstraction, with a maximum concentration of about $7 \mathrm{ppb}$ in both experiments, which is in good agreement with the maximum concentration calculated in the simulations. The yield of benzaldehyde from the reaction of toluene with $\mathrm{OH}$ radicals has been measured in a number of studies under a variety of experimental conditions (Calvert et al., 2002) and an average yield of $10 \%$ is assumed in the MCM mechanism (Jenkin et al., 2003). Therefore the agreement between the measured and modelled concentrations in this case demonstrates the agreement of the $\mathrm{GC} \times \mathrm{GC}$ measurements with previous studies of toluene oxidation. Yields of other products have been much less well determined in the past. It is clear that the model significantly overpredicts the concentrations of $p$-methylbenzoquinone and $\alpha$ angelicalactone/4-oxo-2-pentenal. The model also predicts significant production of other products for which standards have been studied, but which are not identified in the experiments. The modelled peak concentration of butenedial in these experiments is around $1 \mathrm{ppb}$, and the peak concentrations of 5H-furan-2-one and 2,3-epoxybutandial are predicted to be about $2.5 \mathrm{ppb}$. As discussed above for the benzene oxidation experiment these concentrations are significantly above the detection limit of the technique; the implication is that the model over-predicts their concentrations.
Maleic anhydride and citraconic anhydride are not included in the comparison as they were identified only in the high $\mathrm{NO}_{\mathrm{x}}$, VOC limited regime, and the citraconic anhydride peak has not been calibrated and is presented in Fig. 4 as a peak area. The modelled peak concentration of maleic anhydride in the high $\mathrm{NO}_{\mathrm{x}}$ regime is $3.7 \mathrm{ppb}$, and within the error limits is in agreement with the measured peak of $1.6 \mathrm{ppb}$. The simulated concentrations of both anhydride compounds in the moderate $\mathrm{NO}_{\mathrm{x}}$ regime are about $60 \%$ of those predicted in the high $\mathrm{NO}_{\mathrm{x}}$ regime, and it seems that these compounds were formed in too low a concentration to be observed in the moderate $\mathrm{NO}_{\mathrm{x}}$ experiment.

Benzaldehyde, once formed, appears to be lost slowly when compared to the 2-methylbenzoquinone and the angelicalactone/4-oxo-2-pentenal pair, reflecting the lower reactivity of benzaldehyde. The rate constant for $\mathrm{OH}$ reaction with benzaldehyde (Calvert et al., 2002) is a factor of 5 lower than for $\alpha$-angelicalactone and a factor of 4 lower than for 4-oxo-2-pentenal, which also undergoes significant loss by photolysis (Bierbach et al., 1994). The lactone/oxopentenal pair is formed earlier in the reaction than the 2-methylbenzoquinone, maleic and citraconic anhydride, suggesting the latter are second or higher generation products, as indicated in the degradation mechanism shown in Fig. 1. 


\section{$4.3 \quad p$-Xylene Oxidation Products}

Three reaction intermediates were identified for $p$-xylene; citraconic anhydride and the $E$ - and $Z$-isomers of hex-3-ene2,5-dione. Figure 6 shows the evolution of intermediates and the consumption of $p$-xylene under low $\mathrm{NO}_{\mathrm{x}}$ conditions. The two isomers of hex-3-ene-2,5-dione follow the same reaction profile with the $Z$-isomer being formed in larger quantities. This is qualitatively consistent with work carried out by Smith et al. (1999) in which both isomers were identified as primary products in the $\mathrm{OH}$-initiated degradation of $p$ xylene, the $Z$-isomer with a yield of $18 \%$ and the $E$-isomer $5 \%$. The simulation treats both isomers as a single compound and the modelled concentration-time profile is shown in Fig. 6 as a solid black line. The estimated error limits shown as shaded grey areas were calculated by varying the loss rates as indicated in Table 4. The simulated peak concentration occurs earlier than observed and is 30 times higher than the sum of the measured concentrations of the two isomers. In MCMv3 it is assumed that hex-3-ene-2,5-dione is the only co-product of glyoxal in the peroxide-bicyclic ring-opening route and has a yield of $28 \%$, in reasonable agreement with the yields reported by Smith et al. (1999). This conclusion is clearly not supported by the results of this work.

A further product was apparent in the $\mathrm{GC} \times \mathrm{GC}$ chromatogram, but this peak did not correspond to any of the intermediates under investigation. None of the other expected major products of p-xylene oxidation were included in the standard mixtures studied but many are structurally similar to the standard compounds. The retention properties of this peak suggest a volatility between maleic anhydride and $\alpha$-angelicalactone and a polarity similar to the lactone. Using the calibration factor for $\alpha$-angelicalactone gives a maximum concentration of approximately $1.5 \mathrm{ppb}$. A possible assignment for this unknown is 3-methyl-5H-furan-2one, included in MCMv3 as a co-product of methyl-glyoxal in the peroxide-bicyclic ring-opening route of $p$-xylene; its predicted peak concentration in this experiment was $4.8 \mathrm{ppb}$.

\subsection{1,3,5-Trimethylbenzene Oxidation Products}

Seven products were detected in the reaction of $1,3,5-$ trimethylbenzene $(1,3,5-\mathrm{TMB})$ under low and moderate $\mathrm{NO}_{\mathrm{x}}$ conditions. Three products were identified using standard mix retention behaviours (3,5-dimethylbenzaldehyde, 3,5dimethyl- $(5 \mathrm{H})$-furan-2-one and 3-methyl-5-methylene-5Hfuran-2-one) and work is ongoing to identify the unknown products. The same reaction products were also identified in the dark reaction carried out using 2,3-dimethyl-2-butene as the $\mathrm{OH}$ source and in the replacement $\mathrm{NO}_{\mathrm{x}}$ reaction.

A comparison of the evolution of the identified species in the four reactions of 1,3,5-TMB is shown in Fig. 7. Calibrations have been carried out for the 3,5-dimethylbenzaldehyde only and thus area responses are given for uncalibrated species allowing comparison of relative amounts of analytes in different experiments. The simulated concentration-time profiles for 3,5-dimethylbenzaldehyde and 3,5-dimethyl$(5 \mathrm{H})$-furan-2-one are shown for the photo-oxidation experiments.

3-Methyl-5-methylene-5H-furan-2-one was found in the moderate $\mathrm{NO}_{\mathrm{x}}$ regime only and is not included in the MCM degradation scheme. A delay in the growth of carbonyl-type products is evident in the dark, with most products having maximum concentration at the end of the reaction.

In contrast to the toluene case the model-measurement agreement for the benzaldehyde product in these 1,3,5-TMB experiments is poor; the model significantly over-predicts the concentration in all cases and the observed relative concentrations are also not reproduced by the models. The product yields for 1,3,5-TMB are not as well known as for toluene, and the 3,5-dimethylbenzaldehyde yield has been reported in only one study (Smith et al., 1999). This value of 3\% is used in the MCMv3 degradation scheme, but the evidence of this work suggests an even lower yield for the $\mathrm{H}$-abstraction pathway. Substantial concentrations of 3,5dimethyl-(5H)-furan-2-one are predicted by the simulations; it is assumed to be one of two co-products of methylglyoxal in the peroxide-bicyclic ring-opening route, the other being 2-methyl-4-oxo-2-pentenal, and both these products are assigned a $39.5 \%$ yield. The 3,5-dimethyl-(5H)-furan-2-one peaks have not been calibrated but using the calibration factor for $\alpha$-angelicalactone gives a maximum concentration in the dark experiment of approximately $7 \mathrm{ppb}$, suggesting a significant over prediction of the concentration of this compound by the models. One of the unknown peaks in these experiments may correspond to the other proposed co-product of methylglyoxal, 2-methyl-4-oxo-2-pentenal, but no reference standard was available for this compound and its detection could not be confirmed. An alternative co-product for methylglyoxal is 3,5-dimethyl-(3H)-furan-2-one, but this co-elutes with 1,3,5-TMB and therefore it is not possible to identify this product in this work.

As in the p-xylene and toluene mechanisms, citraconic anhydride is expected as a secondary product in the peroxidebicyclic route of 1,3,5-TMB with a predicted peak concentration of about $2 \mathrm{ppb}$. Small peaks with the correct retention behaviour for citraconic anhydride were observed but these overlapped with one of the unknown product peaks and positive identification and quantification of citraconic anhydride was not possible.

Figure 7 also shows a comparison of the 1,3,5-TMB concentrations obtained in the moderate $\mathrm{NO}_{\mathrm{x}}$ using $\mathrm{GC} \times \mathrm{GC}$ and FTIR. Initial concentrations of the parent aromatic are lower than in the toluene comparison and the agreement between the two techniques is good. 

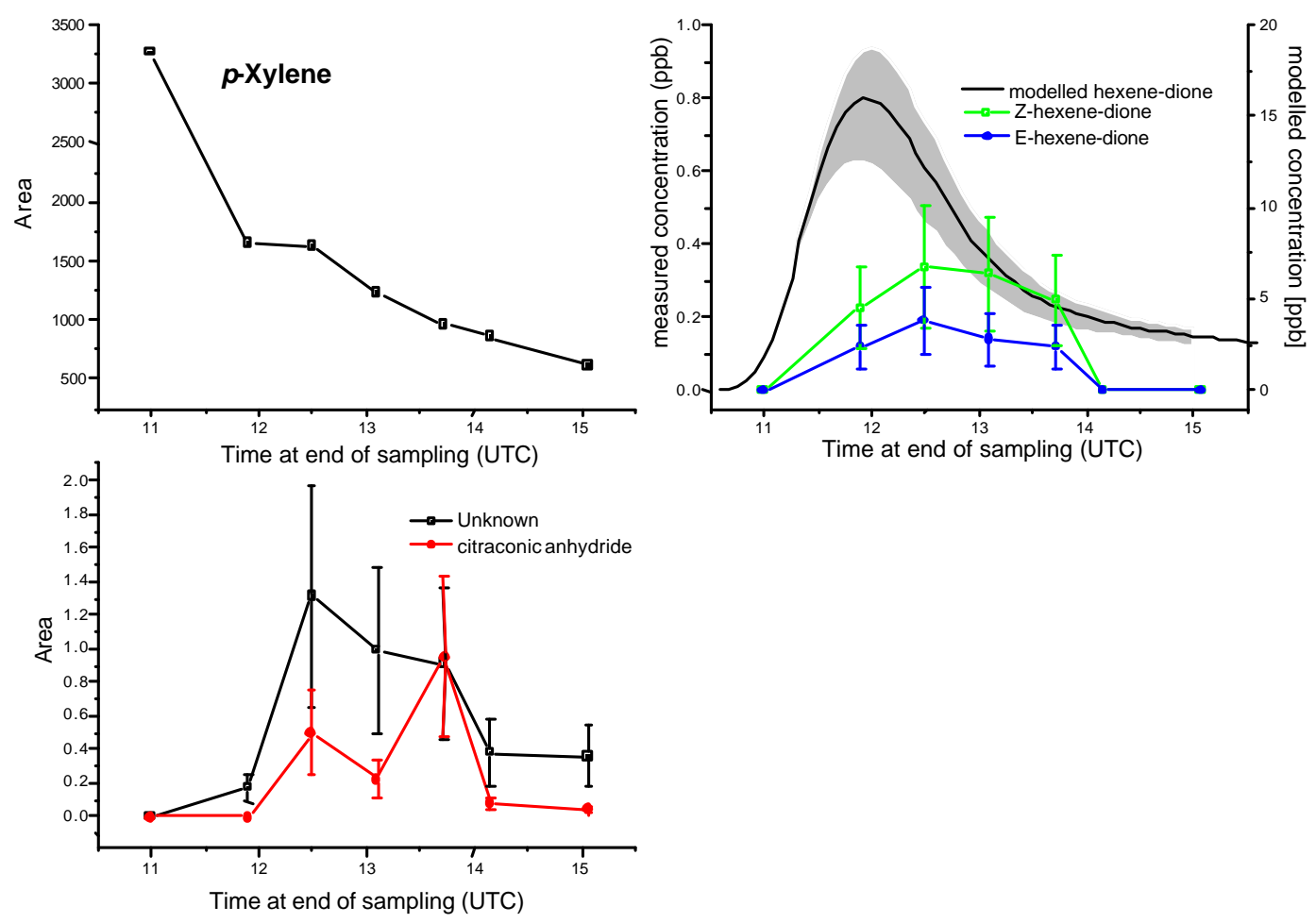

Fig. 6. Experimentally observed concentration-time profiles for parent compound and intermediates the $p$-xylene experiment $(03 / 07 / 02)$. The measured hexene-dione concentration is compared to the MCMv3 simulation which over-predicts the observation by around a factor of 30. Error limits on the experimental points are $\pm 50 \%$ and the estimated error on the simulation shown as shaded grey areas were calculated by varying the loss rates of hexene-dione as indicated in Table 4.

\section{Atmospheric Implications}

The aim of this investigation was to identify and quantify products formed in the atmospheric oxidation of aromatic compounds. Particular focus was placed on the carbonyl products in the ring-opening routes as these have been identified as important radical sources and have a large impact on ozone formation in aromatic photo-oxidation (Wagner et al., 2003). Ring-opened products were detected ; $\alpha$-angelicalactone/4-oxo-2-pentenal, maleic anhydride and citraconic anhydride in the toluene system, hex-3-ene-2,5dione and citraconic anhydride in the $p$-xylene system, 3,5dimethyl-(5H)-furan-2-one and 3-methyl-5-methylene-5Hfuran-2-one in the 1,3,5-trimethylbenzene system, but all were in very low concentration and many other products predicted to occur were not observed. The MCM represents the current best representation of the atmospheric degradation mechanism of aromatic compounds and has been used to calculate photochemical ozone creation potentials to assist policy makers in defining realistic urban smog abatement strategies (Derwent et al., 1998; Jenkin et al., 2003). Some modifications have recently been made from MCMv3, based on some recent experiments, including those conducted during the EXACT campaigns. A significant factor in these revisions was the determination of first generation glyoxal yields in a number of aromatic systems by (Volkamer et al., 2001), with negligible formation in subsequent generations. This revised version of the MCM will be published shortly. While the yields of the carbonyl compounds studied in the present paper are somewhat changed in the new mechanism, the conclusion that the current mechanisms of aromatic oxidation substantially overestimate $\mathrm{C}_{4+}$ carbonyls remains. This observation implies that the co-products of glyoxal, which is itself well established experimentally and a key observable in determining the yield of the peroxy bicyclic route, have not been quantitatively determined. The details of this essential component of the mechanisms therefore remain uncertain. Further work is clearly required to identify the missing products before accurate mechanisms can be constructed and reliable calculations of the effects of aromatic oxidation on the formation of photochemical smog can be made.

\section{Conclusions}

This paper describes the application of comprehensive gas chromatography $(\mathrm{GC} \times \mathrm{GC})$ to the study of the complex mechanisms of atmospheric oxidation of aromatic compounds. This technique is particularly suited to such studies, in which a large number of species are formed in low 

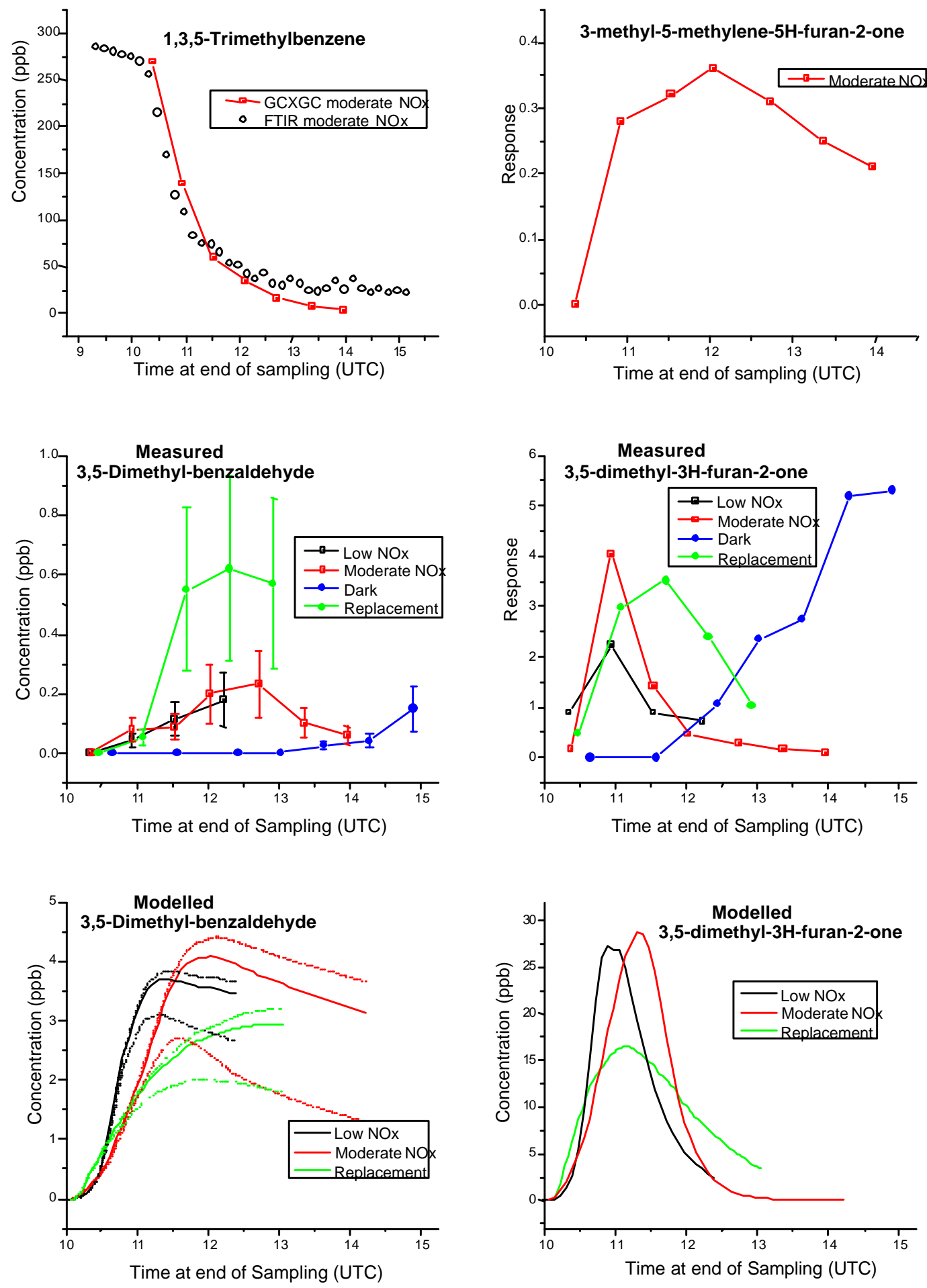

Fig. 7. Experimentally observed concentration-time profiles from 1,3,5-TMB experiments under different conditions. The concentration of the parent compound obtained by $\mathrm{GC} \times \mathrm{GC}$ in the moderate $\mathrm{NO}_{\mathrm{x}}$ experiment is compared to FTIR measurements and shows good agreement. The simulated concentrations of 3,5-dimethylbenzene and 3,5-dimethyl-3H-furan-2-one are shown in the bottom panel for comparison and the estimated error limits on the 3,5-dimethylbenzene simulations are shown as dotted lines. Errors for 3,5-dimethyl-3H-furan-2-one are omitted for clarity. 


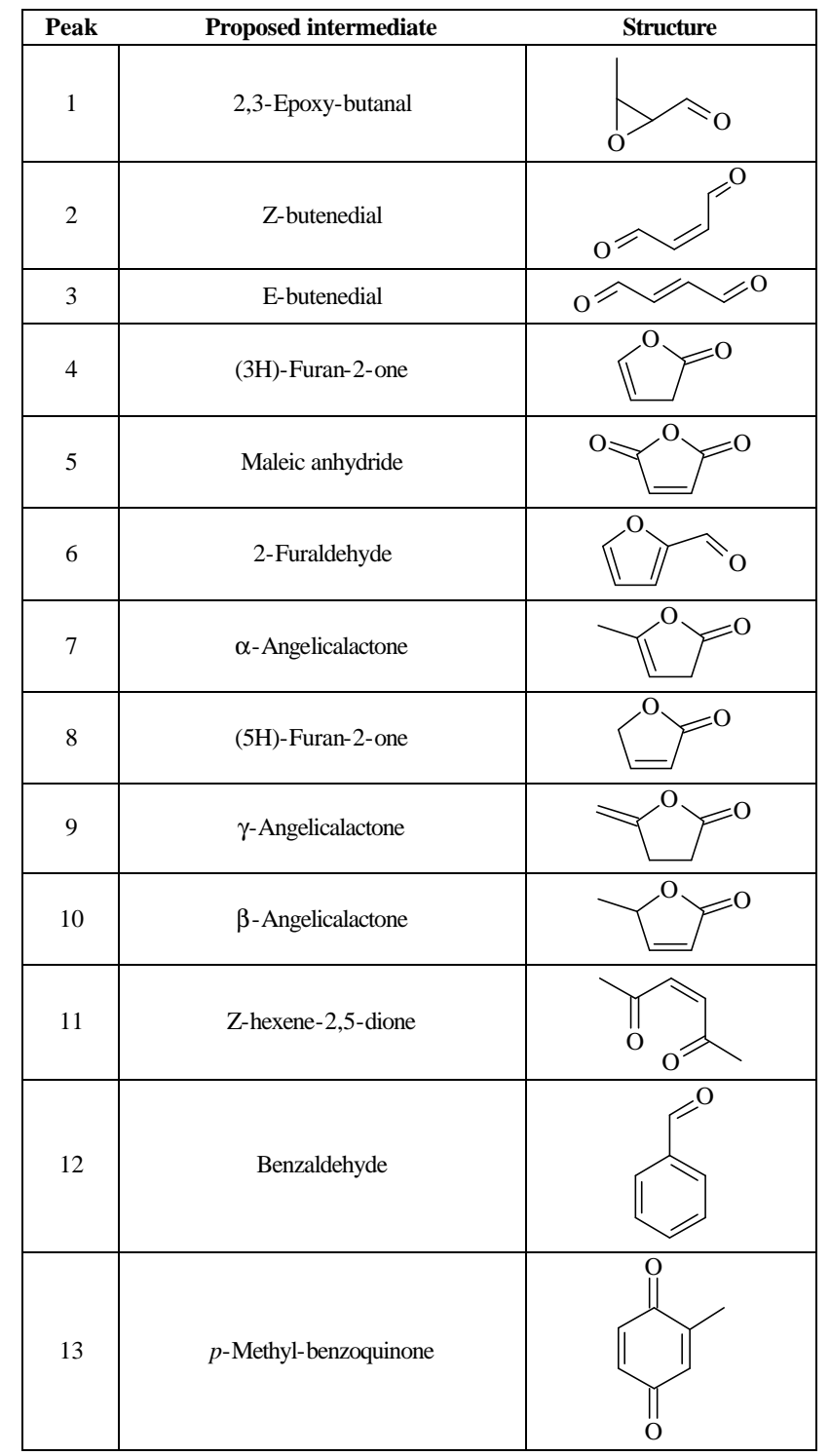

Appendix 1

concentration, because it is able to separate products which co-elute with conventional methodologies and provides increased sensitivity over single dimensional chromatography. The sampling time used was thirty minutes, and between four and eight samples were taken during each experiment, allowing the time dependent behaviour of each species to be observed, and thus facilitating identification of first and subsequent generation intermediates.

Products were observed in smog-chamber studies of the photo-oxidation of four compounds, benzene, toluene, $p$ xylene and 1,3,5-trimethylbenzene, and in most cases these products could be identified and quantified by use of liquid calibration standards. When an observed product did not correspond to one of the standards studied an indication of its structure could be derived from the retention time in the second dimension of the chromatogram which is related to

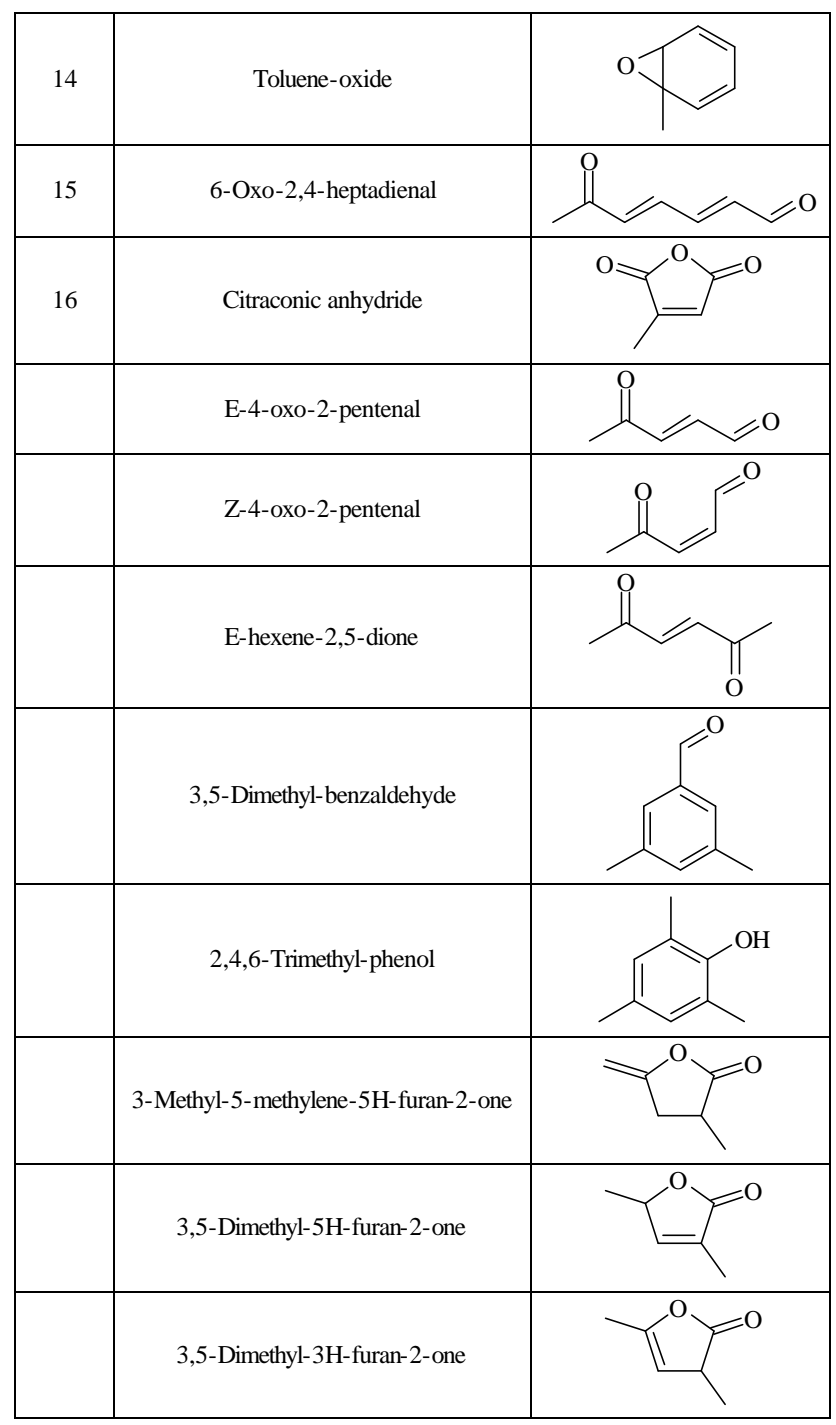

Appendix 2

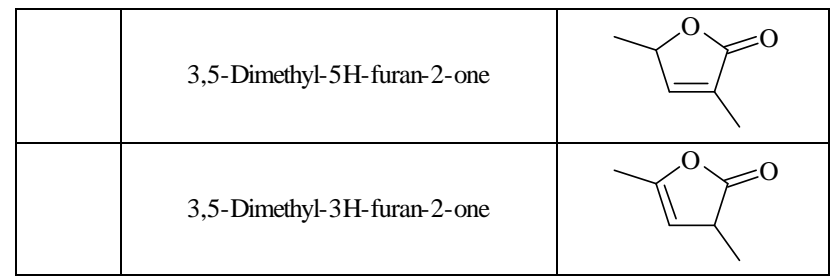

Appendix 3

the polarity of the compound. From a consideration of the expected intermediates in these systems a tentative assignment of some of these unknowns was made and future verification is possible, depending on the availability of suitable standards.

The $\mathrm{GC} \times \mathrm{GC}$ technique was validated in a number of ways. Known quantities of the intermediates were introduced into the chamber, and these gas phase calibrations 
were in reasonable agreement with the calibrations obtained using liquid standard mixtures. The concentration-time profiles of the parent aromatic compounds were measured by $\mathrm{GC} \times \mathrm{GC}$ and by FTIR, and the agreement between the two techniques was good. In addition, the observed concentration of benzaldehyde from the oxidation of toluene, studied in two experiments, is consistent with the yield reported in several previous studies.

Comparison of the concentrations observed by $\mathrm{GC} \times \mathrm{GC}$ to concentration-time profiles simulated using MCMv3 demonstrates that this mechanism significantly over-predicts the concentrations of many product compounds and highlights the uncertainties which exist in our understanding of the atmospheric oxidation of aromatics.

Acknowledgements. J. Hamilton acknowledges an EPSRC studentship. This work has been funded jointly by UK Engineering and Physical Sciences Research Council and Natural Environment Research Council through projects GR/R25804/01 and NER/T/S/2000/01182. Fundacion CEAM is supported by the Generalitat Valenciana and BANCAIXA. This work has been financed by the EC (EVK2-1999-00332) and MCYT (REN20003277-CE/CLI).

\section{References}

Adger, B. M., Barrett, C., Brennan, J., McKervey, M. A. and Murray, R. W.: Oxidation of furans with dimethyldioxirane, Journal of the Chemical Society-Chemical Communications, (21), 15531554, 1991.

Becker, K. H.: EUPHORE: Final Report to the European Commission, Contract \#EV5V-CT92-0059, Bergische Universität Wuppertal, Germany, 1991.

Bierbach, A., Barnes, I., Becker, K. H., and Wiesen, E.: Atmospheric Chemistry of Unsaturated Carbonyls - butenedial, 4-oxo-2-pentenal, 3-hexene-2,5-dione, maleic-anhydride, 3Hfuran-2-one, and 5-methyl-3H-furan-2-one, Environ. Sci. Technol., 28(4), 715-729, 1994.

Bleasdale, C., Cameron, R., Edwards, C., and Golding, B. T.: Dimethyldioxirane converts benzene oxide/oxepin into (Z,Z)-muconaldehyde and sym-oxepin oxide: Modeling the metabolism of benzene and its photooxidative degradation, Chemical Research in Toxicology, 10(12), 1314-1318, (1997).

Buchta, E. and Satzinger, G.: 2-methylprotoanemonen and 2,2dimethylanemonen, Chem. Ber., 92, 471-474, 1995.

Calvert, J. G., Atkinson, R., Becker, K. H., Kamens, R. M., Seinfeld, J. H., Wallington, T. J., and Yarwood, G.: The Mechanisms of Atmospheric Oxidation of Aromatic Hydrocarbons, Oxford University Press, 2002.

Ceroni, M. and Sequin, U.: Determination of the Relative Configurations in the Side-Chains of the Antibiotics Hedamycin and Pluramycin-a - Synthesis and Nmr - Data of Suitable Model Compounds, Helvetica Chimica Acta, 65(1), 302-316, 1982.

Derwent, R. G., Jenkin, M. E., and Saunders, S. M.: Photochemical ozone creation potentials for a large number of reactive hydrocarbons under European conditions, Atmos. Environ., 30(2), 181-199, 1996.
Derwent, R. G., Jenkin, M. E., Saunders, S. M., and Pilling, M. J.: Photochemical ozone creation potentials for organic compounds in northwest Europe calculated with a master chemical mechanism, Atmos. Environ., 32(14-15), 2429-2441, 1998.

Dumdei, B. E., Kenny, D. V., Shepson, P. B., Kleindienst, T. E., Nero, C. M., Cupitt, L. T., and Claxton, L. D.: Ms Ms Analysis of the Products of Toluene Photooxidation and Measurement of Their Mutagenic Activity, Environ. Sci. Technol., 22(12), 1493 1498, 1988.

Graedler, F. and Barnes, I.: Photolysis of Z-/E-3-Hexenedione, EUPHORE report 1997: 148, 1997.

Gunther, H. J., Guntrum, E., and Jager, V.: Synthesis of 4-penten4-olides (Gamma-Methylene-Gamma- Butyrolactones) Via 4 pentenoic Acids, Liebigs Annalen Der Chemie(1), 15-30, 1984.

Jenkin, M. E., Saunders, S. M., Wagner, V., and Pilling, M. J.: Protocol for the development of the Master Chemical Mechanism, MCM v3 (Part B): tropospheric degradation of aromatic volatile organic compounds, Atmos. Chem. Phys., 3, 181-193, 2003.

Klotz, B., Barnes, I., Becker, K. H., and Golding, B. T.: Atmospheric Chemistry of benzene oxide/oxepin, J. Chem. Soc.Faraday Trans., 93, 1507-1516, 1997.

Klotz, B., Barnes, I., Golding, B. T., and Becker, K. H.: Atmospheric chemistry of toluene-1,2-oxide/2-methyloxepin, Phys. Chem. Chem. Phys., 2(2), 227-235, 2000.

Klotz, B., Sorensen, S., Barnes, I., Becker, K. H., Etzkorn, T., Volkamer, R., Platt, U., Wirtz, K., and Martin-Reviejo, M.: Atmospheric oxidation of toluene in a large-volume outdoor photoreactor: In situ determination of ring-retaining product yields, J. Phys. Chem., A 102(50), 10 289-10 299, 1998.

Lee, A. L., Bartle, K. D., and Lewis, A. C.: A model of peak amplitude enhancement in orthogonal two-dimensional gas chromatography, Analytical Chemistry, 73, 1330-1335, 2001.

Liu, Z. Y. and Phillips, J. B.: Comprehensive 2-dimensional gaschromatography using an on-column thermal modulator interface, Journal of Chromatographic Science, 29(6), 227-231, 1991.

Nadkarni, D. V. and Sayre, L. M.: Structural Definition of Early Lysine and Histidine Adduction Chemistry of 4-hydroxynonenal, Chemical Research in Toxicology, 8(2), 284-291, 1995.

Nasman, J. A. H. and Pensar, K. G.: An Improved One-Pot Preparation of 2-furanones, Synthesis-Stuttgart, (8), 786-788, 1985.

Smith, D. F., Kleindienst, T. E., and McIver, C. D.: Primary product distributions from the reaction of $\mathrm{OH}$ with $m-$, $p$-xylene, 1,2,4and 1,3,5-trimethylbenzene, J. Atmos. Chem., 34(3), 339-364, 1999.

Smith, D. F., McIver, C. D., and Kleindienst, T. E.: Primary product distribution from the reaction of hydroxyl radicals with toluene at ppb $\mathrm{NO}_{\mathrm{x}}$ mixing ratios, J. Atmos. Chem., 30(2), 209-228, 1998.

Thuener, L. P., Rea, G., Wenger, J., Henderson, A. P., Bleasdale, C., and Golding, B. T.: Photolysis of Butenedial and 4-oxopent-2enal under atmospheric conditions, Environ. Sci. Technol., submitted, 2003.

Thiele, P., Tischbein, R., and Lossow, E.: Über die Angelicalactone, Justus Liebigs Ann. Chem., 319, 180-195, 1901.

Torii, S., Inokuchi, T., and Kondo, K.: Synthesis of Lepiochlorin, a Chlorinated Antibiotic, by Use of Electrochemical Haloalkoxylation, Bulletin of the Chemical Society of Japan, 56(7), 21832184, 1983.

Volkamer, R., Klotz, B., Barnes, I., Imamura, T., Wirtz, K., 
Washida, N., Becker, K. H., and Platt, U.: OH-initiated oxidation of benzene - Part I. Phenol formation under atmospheric conditions, Phys. Chem. Chem. Phys., 4(9), 1598-1610, 2002.

Volkamer, R., Platt, U., and Wirtz, K.: Primary and secondary glyoxal formation from aromatics: Experimental evidence for the bicycloalkyl-radical pathway from benzene, toluene, and $p$ xylene, J. Phys. Chem., A 105(33), 7865-7874, 2001.

Wagner, V., Jenkin, M. E., Saunders, S. M., Stanton, J., Wirtz, K., and Pilling, M. J.: Modelling of the photooxidation of toluene: conceptual ideas for validating detailed mechanisms, Atmos. Chem. Phys., 3, 89-106, 2003.
Xu, G. Z., Liu, Y. H., and Sayre, L. M.: Independent synthesis, solution behavior, and studies on the mechanism of formation of a primary amine-derived fluorophore representing cross-linking of proteins by (E)-4-hydroxy-2-nonenal, Journal of Organic Chemistry, 64(16), 5732-5745, 1999.

Yu, J. Z. and Jeffries, H. E.: Atmospheric photooxidation of alkylbenzenes, 2. Evidence of formation of epoxide intermediates, Atmos. Environ., 31, 2281-2287, 1997. 